\title{
Abscesso laríngeo de prega vestibular
}

Laryngeal abscess in the vestibular fold

Rodrigo Castro ${ }^{1}$, Christiana Maria dos Santos Vanni', Alexandre Bezerra dos Santos ${ }^{1}$, Jossi Ledo Kanda ${ }^{1}$

\section{Resumo}

Introdução: Os abscessos laríngeos podem ser considerados uma raridade clínica atualmente, devido principalmente ao aumento do uso de antibióticos, bem como seus espectros de ação. Na era pré-antibiótica era um problema relativamente comum, com uma taxa de mortalidade próxima a 100\%. A localização mais frequente dos abscessos na laringe é a região supraglótica periepiglótica, sendo extremamente incomuns em outras regiões. Em ampla revisão literária, não foi encontrado nenhum caso de abscesso laríngeo na prega vestibular. Relato de caso: Paciente do sexo masculino, 31 anos, cantor, procurou nosso serviço com quadro de um dia de odinofagia, disfagia e disfonia. Refere tabagismo e etilismo social. Na laringoscopia direta, observou-se edema e hiperemia importantes da prega vestibular direita, com abaulamento local. A tomografia computadorizada mostrou área hipoatenuante em prega vestibular direita, estabelecendo o diagnóstico. 0 paciente foi submetido à drenagem cirúrgica e recebeu antibioticoterapia. Apresentou boa evolução, com resolução dos sintomas em três dias. Discussão: 0 abscesso laríngeo deve ser um diagnóstico diferencial em casos de maior severidade de uma laringite comum. Na maioria dos casos, o tratamento clínico resolve o caso, mas uma abordagem cirúrgica pode ser necessária, especialmente para descartar neoplasias ou outras alterações anatômicas da laringe. A perviedade da via aérea deve estar garantida. A evolução é boa, se o tratamento é prontamente estabelecido.

Palavras-chave: Abscesso; laringe; prega vestibular; laringoscopia.

\begin{abstract}
Introduction: Laryngeal abscesses can be considered clinical rarities nowadays, mainly due to the increase of the use of antibiotics and their spectrum of action. In the pre-antibiotic era, this problem was relatively usual, with a mortality rate close to $100 \%$. The most frequent site where the abscesses occur in the larynx is the supraglotic (periepiglotic) region, and they are extremely rare in other regions. In the literary revision, no report of laryngeal abscess in vestibular fold was found. Case report: Male, 31 years old, singer, presenting at our institution with odynophagia, dysphagia and aphonia for one day. Consumption of alcohol and tobacco is related as frequent. Direct laryngoscopy revealed significant edema and hyperemia of right vestibular fold and bulging in the region. Computadorized tomography showed hypoattenuation of the vestibular fold, establishing the diagnosis. The patient was submitted to surgical approach, with drainage of the abscess, and antibiotics were prescribed. The outcome was good, with resolution of the symptoms in three days. Discussion: The laryngeal abscesses must be a differential diagnosis in cases of major severity of a single laryngitis. In the majority of patients, the clinical treatment may solve the case, but the surgical approach is sometimes necessary, specially to discharge neoplasms, or other anatomic alterations of the larynx. The upper airway must be assured. The outcome is good, if the treatment is promptly established.
\end{abstract}

Keywords: Abscess; larynx; vestibular fold; laryngoscopy.

Recebido: $11 / 3 / 2009$

Revisado: $31 / 8 / 2009$

Aprovado: 6/10/2009

\footnotetext{
Trabalho realizado no Serviço de Cirurgia de Cabeça e Pescoço da Faculdade de Medicina do ABC (FMABC) - Hospital de Ensino Padre Anchieta, São Bernardo do Campo (SP), Brasil

Disciplina de Cirurgia de Cabeça e Pescoço da Faculdade de Medicina do ABC (FMABC), Santo André (SP), Brasil

Endereço para correspondência: Rodrigo Castro - Avenida Lauro Gomes, 2000 - Rudge Ramos - CEP 09060-870 - Santo André (SP) - E-mail: rodrigo-

castroabc@gmail.com
} 


\section{Introdução}

Atualmente, os abscessos laríngeos são considerados uma entidade clínica incomum, devido ao uso disseminado de antibióticos, além do aumento do aspecto de ação desses. Na era pré-antibiótica, era um problema relativamente comum, com uma taxa de mortalidade próxima aos $100 \%{ }^{1}$

De maneira geral, os abscessos laríngeos estão relacionados a alterações anatômicas da laringe, como traumatismos, cirurgias, corpos estranhos, laringoceles, cistos e câncer (com ou sem radioterapia); ou a fatores sistêmicos, como imunossupressão. A ocorrência de abscessos laríngeos espontâneos é considerada excepcional².

Na era pré-antibiótica, a Salmonella typhi era o patógeno mais comum. E muitas vezes, em associação com outras doenças infecciosas como gonorreia, sífilis, tuberculose, erisipela, difteria e antraz ${ }^{3}$.

Atualmente, a flora bacteriana tem sofrido muitas modificações, devido à expansão da era vacinal e pela antibioticoterapia disponível. Assim, os pneumococos, os estreptococos e os estafilococos são os mais encontrados ${ }^{4}$, seguido de outros patógenos: o Branhamella catarralis e o Haemophylus influenzae. Além disso, é comum encontrar flora polimicrobiana, muitas vezes em associação com bactérias anaeróbicas ${ }^{5}$.

A localização mais frequente dos abscessos na laringe é a região supraglótica periepiglótica, como complicação de epiglotite, sendo extremamente infrequentes em outras regiões ${ }^{6}$. Após ampla revisão de literatura, não foi encontrado nenhum caso descrito de um abscesso originado na prega vestibular.

Com a aprovação do Comitê de Ética da Faculdade de Medicina do $\mathrm{ABC}$, pelo protocolo 333-2008, relatamos o caso de um paciente com diagnóstico de abscesso laríngeo.

\section{Relato de caso}

Paciente do sexo masculino, 31 anos, caucasiano, cantor, admitido ao Serviço de Cirurgia de Cabeça e Pescoço da Faculdade de Medicina do $\mathrm{ABC}$, em caráter de urgência, com quadro de um dia de odinofagia, disfagia intensa e disfonia. Negava febre. Referia tabagismo crônico (de 50 a 60 cigarros/dia) há 15 anos e etilismo social. Nega comorbidades, traumas ou cirurgias prévias.

O exame de laringoscopia direta mostrou edema e hiperemia importantes de prega vestibular direita, além de abaulamento de aproximadamente $4 \mathrm{~mm}$, sugestivo de abscesso fechado. A mobilidade da glote estava preservada. Não havia sinais de obstrução de vias aéreas (Figura 1).

Os exames laboratoriais mostravam uma leucocitose de 12.600/ $\mathrm{mm}^{3}$, com $4 \%$ de bastonetes. A tomografia computadorizada de região cervical, com contraste, evidenciou área hipoatenuante em prega vestibular direita e edema importante da região glótica (Figura 2).

Estabelecido o diagnóstico, o paciente foi submetido à laringoscopia de suspensão, em caráter de urgência, e drenagem da prega vestibular com saída de pequena quantidade de secreção purulenta. Foi também realizada biópsia da lesão, a fim de descartar neoplasia, além da administração de antibioticoterapia endovenosa (ceftriaxone e clindamicina).

O paciente apresentou boa evolução clínica, com rápida melhora dos sintomas, sendo submetido, no $3^{\circ} \mathrm{PO}$, à laringoscopia direta que mostrou regressão do edema e resolução do abscesso (Figura 3). Recebeu alta médica e completou antibioticoterapia em esquema domiciliar.

$\mathrm{O}$ anatomopatológico mostrou um processo inflamatório inespecífico. Após duas semanas, no retorno ambulatorial, o paciente apresentava resolução total do quadro.

\section{Comentários}

$\mathrm{Na}$ literatura consultada, a grande maioria dos casos se apresentaram associados a traumatismos laríngeos por intubação endotraque$\mathrm{al}^{7-8}$, ou alimentação mediante a sonda nasogástrica ${ }^{8-9}$, ou por corpos estranhos ${ }^{10}$, tratamento imunossupressor, doenças autoimunes (como o lúpus eritematoso sistêmico ou diabetes mellitus $)^{11}$, radioterapia cervi-

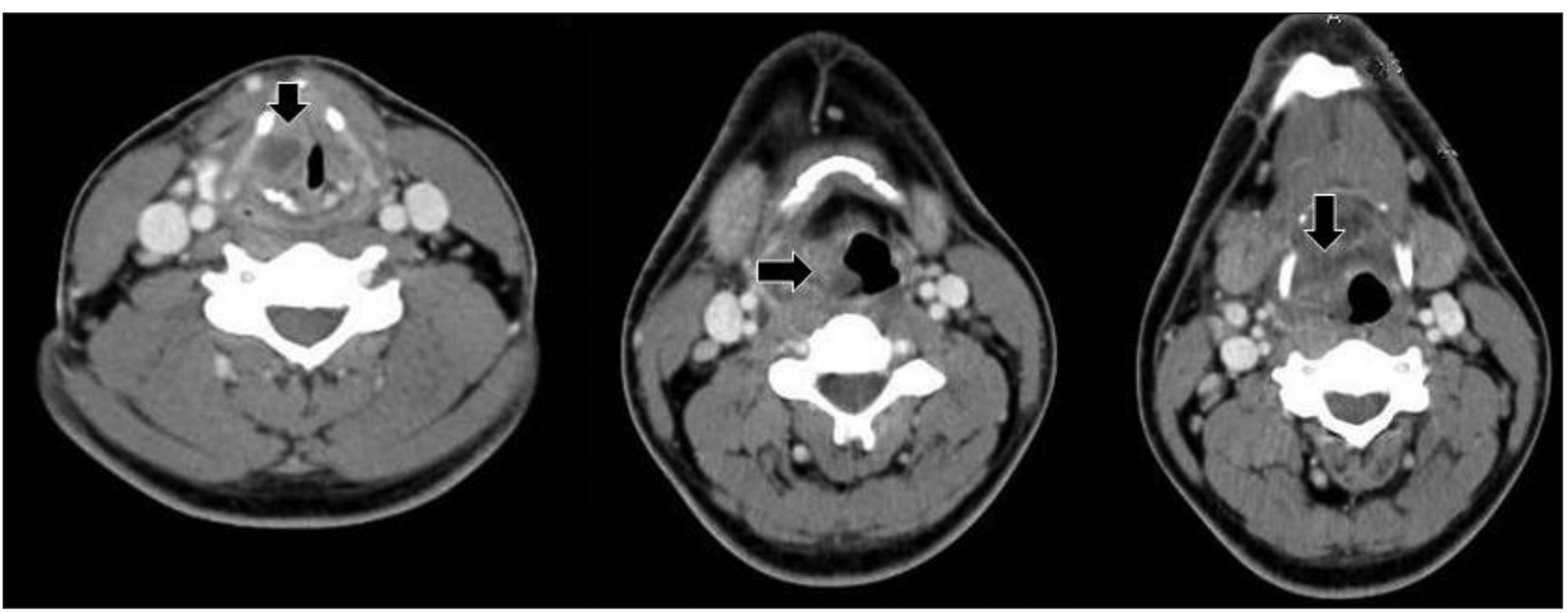

Figura 1 - Laringoscopia; abscesso laríngeo evidenciado pelas setas 


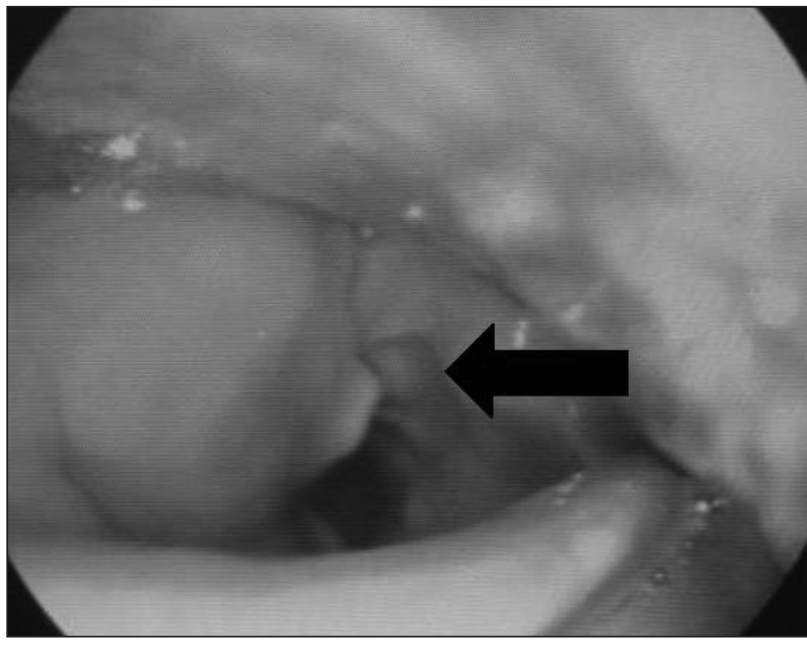

Figura 2 - Tomografia computadorizada de região cervical, evidenciando abscesso em prega vestibular direita e edema da região glótica (seta)

$\mathrm{cal}^{1}$, laringocele ou epiglotites agudas. Os antecedentes mais descritos foram os traumatismos laríngeos por intubação endotraqueal ou por sonda nasogástrica. No caso apresentado, não houve fatores antecedentes ou predisponentes que estariam claramente associados à formação do abscesso de forma aguda.

Clinicamente, o paciente apresentou um quadro clínico bastante característico com odinofagia, disfagia e disfonia ou afonia. Pode-se apresentar ainda sinais de infecção sistêmica. Em alguns casos, observa-se dispneia ou apneia pela obstrução parcial ou total da laringe. Do ponto de vista clínico, os abscessos de laringe se manifestam de forma semelhante às laringites infecciosas; no entanto, a intensidade dos sintomas é mais intensa e o tempo de instalação é mais curto.

O diagnóstico é confirmado pelos achados laringoscópicos e tomográficos, que mostra a presença de imagem cavitada irregular com margens demarcadas pelo contraste, além de fornecer orientações sobre o tamanho, extensão e possibilidades de lesões associadas ${ }^{12}$. O principal diagnóstico diferencial é o carcinoma de laringe, que pode coexistir com um abscesso ${ }^{13}$. Os abscessos podem ser subdiagnosticados, com risco de evolução para infecções mais profundas e pior prognóstico.

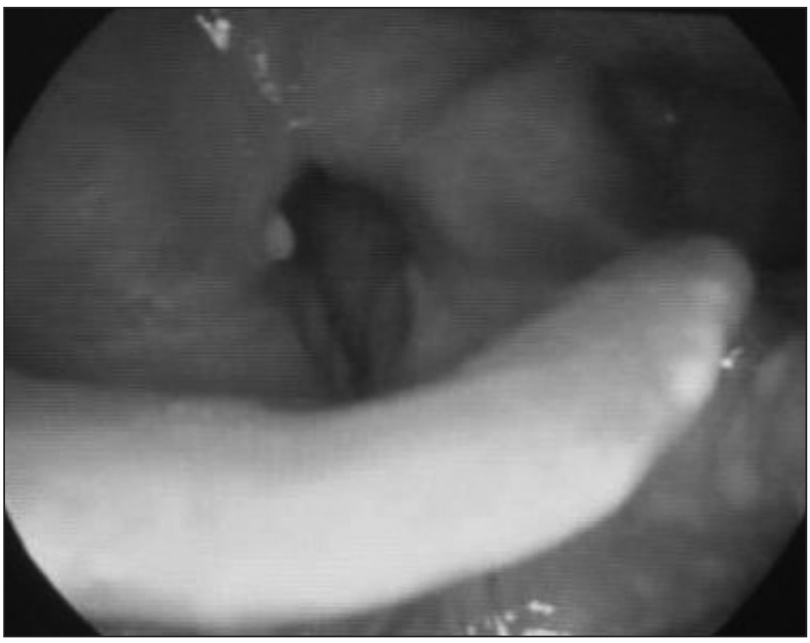

Figura 3 - Pós-operatório mostrando a regressão do edema e resolução do abscesso

O tratamento visa, inicialmente, a garantir a perviedade da via áerea, mediante uma intubação ou traqueostomia, se necessário. Uma vez assegurada à via aérea, é necessário analisar se o processo encontra-se na fase flegmonosa ou abscedada ${ }^{14}$.

Na maioria dos pacientes, o tratamento clínico isolado é satisfatório. Muitos desses pacientes evoluem para a paresia ou paralisia das pregas vocais, o que não foi observado no caso relatado.

Em conclusão, os abscessos laríngeos exigem rápida suspeita diagnóstica, baseado na história muito aguda e exames complementares, e exige tratamento imediato para haver garantia de bom resultado terapêutico. Se houverem alterações estruturais da laringe associadas, devem ser tratadas posteriormente.

Este caso é ilustrativo para a sociedade médica, porque esses pacientes procurararão serviços de atendimento imediato, e passarão em consultas, na maior parte dos casos, com clínicos gerais, que deverão estar atentos à severidades dos sintomas, se comparados com as laringites comuns. Na literatura consultada, não há descrição de nenhum caso de formação de um abscesso laríngeo originário especificamente na prega vestibular.

\section{Referências}

1. Kearnan JD, Schugt HP. Abscess of the larynx and its treatment. Tans Am Laryngol Assoc 1934;56:180-213.

2. Wolf M, Strauss B, Kronenberg J, Leventon G. Conservative management of adult epiglottitis. Laryngoscope 1990;100(2):183-5

3. Jackson C. The larynx in typhoid fever. Am J Med Sci 1905;130: 845-52.

4. Freche $\mathrm{CH}$, Tran Ba Huy P. Laryngites aiguës de I'adulte. In: Encyclopédie de Médecine et Chirurgie. Oto-rhino-laryngologie. Paris: Elsevier; 1997. 20645-A-10.
5. Schalen L, Christensen P, Kamem C. High isolation rate of Branhamella catarralis from the nasopharynx in adults with acute laryngitis. Stand J Infect Dis 1980;12(4):277-80.

6. Heeneman H, Ward KM. Epiglottic abscess: its occurrence and management. J Otolaryngol 1977;6(1):31-6.

7. Canalis RF, Jenkins HA, Osguthorpe JD. Acute laryngeal abscesses. Ann Otol Rhinol Laryngol 1979,88(2):275-9.

8. Clemons JE, Portilla W. Laryngeal abscess. Otolaryngol. Head Neck Surg 1979;87(3):339-41. 
9. Souliere CR, Kirchner JA. Laryngeal perichondritis and abscess. Arch Otolaryngol 1985;111(7):481-4.

10. Ridgeway NA, Perlman PE, Verghese A, Berk SL. Epiglottic abscess due to group B estreptococcus. Ann Oto Rhinol Laryngol 1984;93(3):277-8.

11. McNellis EL, Hoang K-GG. Immunosuppression and systemic lupus erythematosus predisposing to laryngeal abscess. Otolaryngol Head Neck Surg 1997;116(1):107-9.
12. Hawkins DB, Miller AH, Sachs CB, Benz RT. Acute epiglottitis in adults. Laryngoscope 1993;83(8):1211-20.

13. Lee WC, Walsh RM, Tse BM. Squamous cell carcinoma of the pharynx and larynx presenting as a neck abscess or cellulitis. J Laryngol Otol 1996;110(9):893-5.

14. Stack BC, Ridley MB. Epiglottic abscess. Case report. Head Neck 1995;17(3):263-5. 